\title{
IMPACT OF THE SERVICE OF THE EDUCATION GROUP AND ONCOLOGICAL STUDIES ON THE DIAGNOSIS OF BREAST CANCER IN CEARÁ
}

Luiz Gonzaga Porto Pinheiro', Cícera C. Lobo², Paulo Henrique Diógenes Vasques², Márcio Marcondes Vieira²

${ }^{1}$ Universidade Federal do Ceará - Fortaleza (CE), Brazil.

${ }^{2}$ Centro de Oncologia Leonardo Da Vinci - Fortaleza (CE), Brazil.

Introduction: Breast cancer remains the most prevalent in Brazilian women, with the exception of non-melanoma skin cases. Performing disease control uses awareness strategies, clinical criteria for suspected cases, and diagnostic confirmation in a single service (INCA, 2015). The Oncology Education and Studies Group (Grupo de Educação e Estudos Oncológicos - GEEON) is a Reference Service for Breast Cancer Diagnosis (SDM), located in Fortaleza, Ceará. Objectives: To identify the impact of GEEON's SDM on cancer diagnosis in Ceará. Method: Retrospective, evaluative study of the services provided at GEEON in the period from 2016 to 2019. The data underwent univariate statistical analysis. Results: The service grew by $256 \%$ in the number of visits, increasing from 6,758 to 17,301, with a total of 44,309. Mammographic screening is the most frequent procedure, evolving from 2,570 to 9,366 annual exams, with an average of 5,058. It showed a high rate of absenteeism, with an average of $31 \%$ per year. Of the 20,234 mammograms performed, 683 patients (3.4\%) did not receive the result. The average of tests performed was classified as Bi-rads 4 and 5 and was approximately $2 \%$. The mean positive rate of biopsies performed is $31 \%$, resulting in an average of 176 diagnoses per year, which represents $8 \%$ of the total estimated for Ceará. Of these, about $40 \%$ are in women under 50 years of age. The organization of the service along the lines of patient navigation carries out an active search for suspected mammographic lesions for immediate diagnosis, as well as a reference for tertiary care in cases of positive biopsy, through telephone contact. Conclusions: The consultations performed at GEEON identify $8 \%$ of the estimated cases for each year, a high percentage in young women, outside the scope of the screening policies. 